\title{
Upaya Peningkatan Pengetahuan Kader Posyandu dalam Kegiatan Pelatihan Pendampingan Pemberian ASI Eksklusif Di Kelurahan Tataaran II Tondano Selatan Kabupaten Minahasa
}

\author{
Nancy Swanida Henriette Malonda ${ }^{1 *}$, Yulianty Sanggelorang ${ }^{1}$ \\ ${ }^{1}$ Program Studi IKM Fakultas Kesehatan Masyarakat Universitas Sam Ratulangi \\ Penulis korespondensi: Nancy Swanida Henriette Malonda, Program Studi IKM, FKM Unsrat \\ Email: nancymalonda@unsrat.ac.id
}

\begin{abstract}
ABSTRAK
Program peningkatan pemberian Air Susu Ibu (ASI) khususnya ASI eksklusif merupakan program prioritas. Hal ini dikarenakan memberikan dampak luas terhadap status gizi dan kesehatan balita. Peningkatan kapasitas kader posyandu melalui penyuluhan dan pelatihan, diharapkan dapat meningkatkan kesadaran dan pengetahuan masyarakat tentang pemberian ASI Eksklusif. Penyuluhan dan konseling/pendampingan kader dilaksanakan pada bulan Juli 2019, di Kelurahan Tataaran II Kecamatan Tondano Selatan. Sejumlah 28 orang ibu kader Posyandu, diberikan penyuluhan dan dilatih pendampingan pemberian ASI eksklusif pada ibu menyusui. Hasil analisis menunjukkan jumlah nilai rata-rata sebelum pelatihan 76,07 dan setelah pelatihan 93,04 dari rentang nilai $0-100$. Pengetahuan kader diperoleh nilai $\mathrm{p}=0,000(\mathrm{p}<0,05)$ sehingga dapat disimpulkan bahwa terdapat perbedaan pengetahuan yang bermakna antara sebelum diberikan pelatihan ASI eksklusif dengan sesudah pelatihan ASI eksklusif pada kader posyandu. Meningkatnya pengetahuan, dan keterampilan para kader posyandu tentang pemberian ASI eksklusif, dapat meningkatkan pemahaman dan kesadaran para ibu menyusui, sehingga pemberian ASI eksklusif dapat ditingkatkan.
\end{abstract}

Kata kunci: kader posyandu, pelatihan, ASI eksklusif

\begin{abstract}
The program to increase breastfeeding, especially exclusive breastfeeding, was a priority program because it provides a broad impact on the nutritional status and health of toddlers. Increasing public awareness and knowledge about exclusive breastfeeding $y$ increasing the capacity of posyandu cadres through counseling and training. Counseling and cadres counseling/ mentoring was carried out in July 2019, in Tataaran II Sub-District, South Tondano District. A total of 28 Posyandu cadres were provided counseling and trained in the assistance of exclusive breastfeeding. The results of the analysis showed the average number of values before training 76.07 and after training 93.04 from the range of values from 0-100. Cadres knowledge obtained $p=0,000(p<0.05)$ so that it can be concluded that there were significant differences in knowledge between before being given exclusive ASI training and after exclusive ASI training for posyandu cadres. Increased knowledge, and skills of posyandu cadres about exclusive breastfeeding, can increase the understanding and awareness of breastfeeding mothers, so that exclusive breastfeeding can be improved.
\end{abstract}

Keywords: posyandu cadres, training, exclusive breastfeeding 


\section{PENDAHULUAN}

\section{Analisis Situasi}

Program pemberian Air Susu Ibu (ASI) khususnya ASI eksklusif merupakan program prioritas untuk menuntaskan prevalensi gizi kurang dan gizi buruk. Hal ini dikarenakan memberikan dampak luas terhadap status gizi dan kesehatan balita. Didukung pula konferensi tingkat tinggi tentang kesejahteraan anak menyepakati bahwa semua keluarga harus mengetahui arti penting mendukung dalam tugas pemberian ASI saja selama enam bulan untuk perempuan pada kehidupan pertama bagi anak. Bagi ibu dan bayi, ASI eksklusif memudahkan terjalin ikatan kasih sayang yang mesra antara ibu dan bayi baru lahir merupakan keuntungan awal dari menyusui secara eksklusif. Masa menyusui pada anak usia 0-6 bulan merupakan salah satu bagian dari 1000 Hari Pertama Kehidupan yang merupakan periode emas.

Gerakan Nasional Percepatan Perbaikan Gizi yang fokus pada 1000 Hari Pertama Kehidupan (HPK) mengedepankan upaya bersama antara pemerintah dan masyarakat melalui penggalangan partisipasi dan kepedulian pemangku kepentingan secara terencana dan terkoordinasi untuk percepatan perbaikan gizi masyarakat dengan prioritas pada 1000 HPK Pada usia tersebut, bayi masih membutuhkan Air Susu Ibu (ASI) untuk mencukupi kebutuhan gizi mereka dan akan mempengaruhi pertumbuhan dan perkembangan pada usia 24-59 bulan atau pada masa balita (Sudargo et al.,2018).

Status gizi balita di Sulawesi Utara berdasarkan hasil riskesdas tahun 2013 yaitu $3,7 \%$ gizi buruk dan 12,8 gizi kurang; $16,3 \%$ pendek dan $9,5 \%$ sangat pendek; $3,4 \%$ sangat kurus, 6,5\% kurus dan 10,5\% balita gemuk (Fikawati et al.2015).

Anak yang mendapatkan ASI eksklusif atau predominan, mempunyai status gizi yang lebih baik dari pada ASI parsial atau yang diberi makanan/minuman tambahan $<6$ bulan dan yang tidak pernah ASI (Kementerian Kesehatan R.I, 201).

Hasil penelitian yang telah dilakukan di wilayah kerja Puskesmas Koya kecamatan Tondano Selatan Kabupaten Minahasa pada tahun 2018, diperoleh data bahwa $73.3 \%$ anak usia 6-24 bulan, tidak diberikan ASI Eksklusif. Analisis statistik menunjukan bahwa factor pemberian ASI eksklusif ada hubungannya dengan kejadian stunting. Hubungan antara pemberian ASI eksklusif dengan stunting yaitu anak usia 6-24 bulan tersebut 18 kali lebih berisiko stunting pada anak yang tidak mendapatkan ASI eksklusif, dibandingkan dengan anak yang mendapatkan ASI eksklusif (Malonda et al., 2018).

Kerangka Intervensi Stunting yang dilakukan oleh Pemerintah Indonesia terbagi menjadi Intervensi Gizi Spesifik dan Intervensi Gizi Sensitif. Kerangka Intervensi Gizi Spesifik merupakan intervensi yang ditujukan kepada anak dalam 1.000 Hari Pertama Kehidupan (HPK) dan berkontribusi pada $30 \%$ penurunan stunting. Kegiatan yang idealnya dilakukan untuk melaksanakan Intervensi Gizi Spesifik dapat dibagi menjadi beberapa intervensi utama yang dimulai dari masa kehamilan ibu hingga melahirkan balita. Intervensi Gizi Spesifik dengan sasaran Ibu Menyusui dan Anak Usia 0-6 Bulan dilakukan melalui beberapa kegiatan yang mendorong inisiasi menyusui dini/IMD terutama melalui pemberian ASI colostrum serta mendorong pemberian ASI 
saja tanpa ada tambahan makanan lainnya (ASI Eksklusif). Kebijakan pengaturan pemberian ASI Eksklusif adalah untuk menjamin pemenuhan hak bayi untuk mendapatkan ASI eksklusif sejak dilahirkan sampai usia 6 bulan, selain itu juga memberikan perlindungan kepada ibu dalam memberikan ASI eksklusif kepada bayinya, dan meningkatkan peran keluarga, masyarakat, dan pemerintah (Sugihantono, 2017). Fase ketika ibu menyusui 0 sampai dengan 6 bulan, menjadi hal yang penting untuk diperhatikan.

\section{Tujuan dan Manfaat Kegiatan}

Kegiatan pengabdian pada masyarakat ini bertujuan untuk meningkatkan kapasitas kader posyandu melalui penyuluhan dan pelatihan, diharapkan dapat meningkatkan kesadaran dan pengetahuan masyarakat tentang pemberian ASI Eksklusif, sehingga prevalensi pemberian ASI Eksklusif mencapai target $80 \%$.

\section{METODE PELAKSANAAN}

\section{Sasaran kegiatan}

Yang menjadi sasaran pelaksanaan kegiatan pelatihan ini adalah para Kader Posyandu.

\section{Lokasi kegiatan}

Kegiatan dilaksanakan di Balai Pertemuan Kelurahan Tataaran II kecamatan Tondano Selatan kabupaten Minahasa seperti pada Gambar 1.

\section{Metode yang digunakan :}

Kegiatan Program Kemitraan

Masyarakat dilaksanakan dalam bentuk penyuluhan dan konseling/pendampingan kader, dilaksanakan melalui suatu proses pelatihan menggunakan standar modul pelatihan.

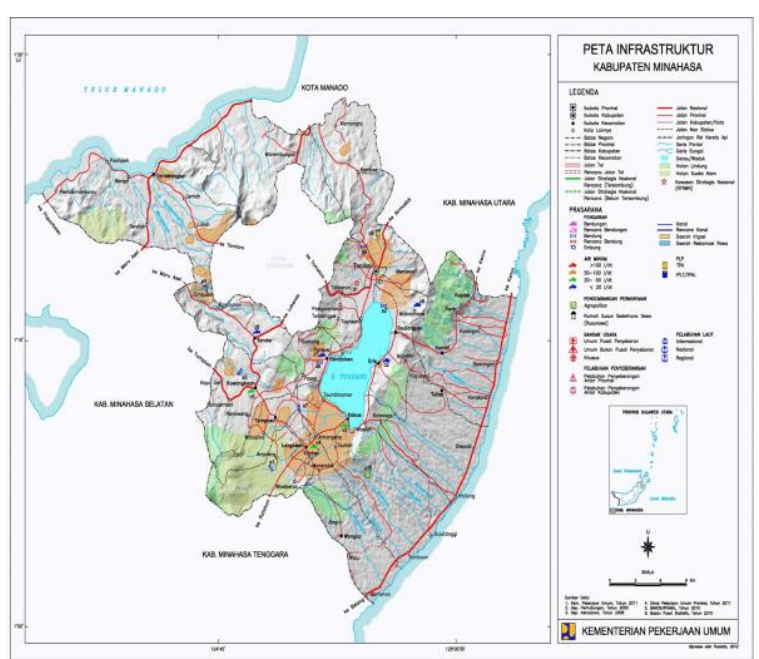

Gambar 1. Peta lokasi kegiatan

Kegiatan dimulai dengan perkenalan, membuat kesepakatan dalam pelatihan, dan pelaksanaan pretest, untuk mengetahui pemahaman awal tentang ASI Eksklusif. Pertanyaan dalam kuesioner terdiri dari pengertian ASI eksklusif, anjuran pemberian ASI eksklusif, manfaat ASI bagi ibu dan bayi, cara meningkatkan produksi ASI, pengertian kolostrum, frekuensi pemberian ASI, dan durasi tiap kali menyusui.

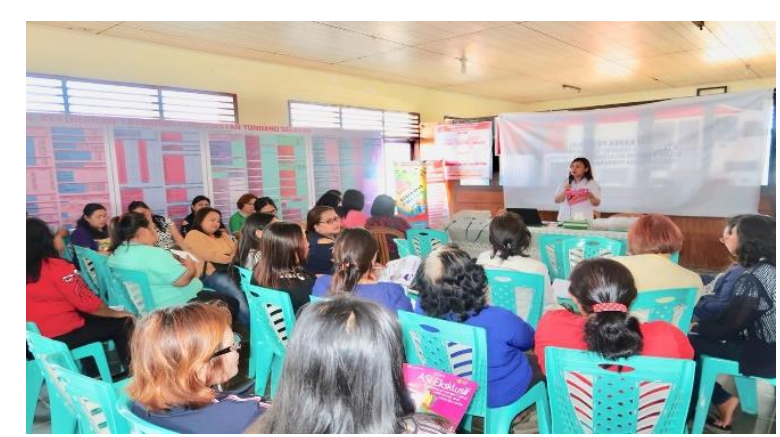

Gambar 2. Pemberian materi mengenai ASI eksklusif oleh narasumber (dr. Nancy S.H Malonda, MPH)

Sejumlah 28 kader posyandu peserta pelatihan, dibagi dalam empat kelompok, 
masing-masing kelompok terdiri dari 7 orang. Narasumber menyampaikan pemaparan materi dengan topik sebagai berikut:

1. Pengertian ASI eksklusif,

2. Inisiasi Menyusu Dini (IMD),

3. Manfaat ASI,

4. Komposisi ASI,

5. Posisi menyusui, dan

6. Persiapan ASI eksklusif untuk ibu bekerja.

Para kader kemudian didampingi fasilitator dalam praktek microteaching, tentang cara memberikan penyuluhan dan pendampingan dalam meningkatkan pemahaman masyarakat tentang ASI Eksklusif. Pada akhir kegiatan, dilaksanakan evaluasi dengan cara melakukan post test.

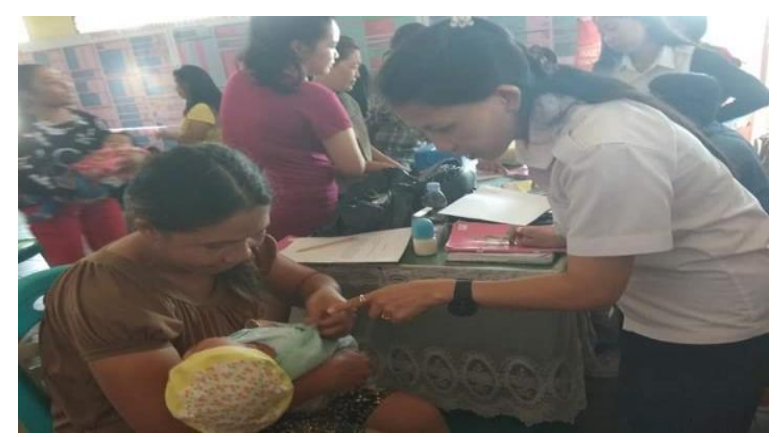

Gambar 3. Praktek microteaching kader yang didampingi oleh fasilitator

\section{HASIL DAN PEMBAHASAN}

Hasil analisis secara deskriptif dan uji statistik menunjukkan jumlah nilai rata-rata sebelum pelatihan 76,07 dan setelah pelatihan 93,04 dari rentang nilai 0-100. Pengetahuan kader diperoleh nilai $\mathrm{p}=$ $0,000(\mathrm{p}<0,05)$ sehingga dapat disimpulkan bahwa terdapat perbedaan pengetahuan yang bermakna antara sebelum diberikan Pelatihan ASI Eksklusif dengan sesudah Pelatihan ASI Eksklusif pada kader posyandu. Sebagian besar kader sudah memiliki pengetahuan yang baik sebelum diberikan penyuluhan/pelatihan, hanya 2 responden yang memiliki pengetahuan kurang. Pengetahuan yang kurang antara lain tentang kolostrum, penyimpanan ASI yang diperah, dan masalah-masalah menyusui pada ibu seperti puting lecet, air susu yang tidak keluar. Secara jelas dapat lihat pada tabel 1.

Tabel 1. Perubahan Tingkat Pengetahuan Peserta Kegiatan PKM

\begin{tabular}{ccccc} 
& \multicolumn{2}{c}{ Post-test } & & \\
\cline { 2 - 3 } Pretest & $\begin{array}{c}\text { Kuran } \\
\text { g Baik }\end{array}$ & Baik & Total & $\begin{array}{c}\mathbf{p}_{\text {value }} \\
*\end{array}$ \\
\hline Kuran & 1 & 12 & 13 & \\
g Baik & $(7,7 \%)$ & $(92,3$ & $(100$ & \\
& & $\%)$ & $\%)$ & \\
Baik & 1 & 14 & 15 & 0,00 \\
& $(6,7 \%)$ & $(93,3$ & $(100$ & 0 \\
Total & 2 & 26 & $\%)$ & \\
& $(7,1 \%)$ & $(92,9$ & $(100$ & \\
& & $\%)$ & $\%)$ & \\
\hline
\end{tabular}

$*_{\alpha}=0,05$

Terdapat pengaruh yang bermakna atara pengetahuan kader, sebelum dan sesudah diberikan pelatihan pemberian ASI. Hasil ini menunjukkan bahwa rendahnya pemberian ASI ekslusif di wilayah kerja PKM Koya kecamatan Tondano Selatan berkaitan dengan pengetahuan yang rendah.

Penelitian yang dilaksanakan tahun 2018 di desa Ratahan Kabupaten Minahasa Tenggara diperoleh data bahwa ada $42 \%$ balita yang tidak mendapatkan ASI eksklusif. Kegagalan pemberian ASI eksklusif dikarenakan pemberian MP-ASI dini yaitu $31,5 \%$ balita mendapatkan MP ASI pada saat usia kurang dari 6 bulan. Sebagian besar balita atau $77,3 \%$ balita tidak mendapatkan 
ASI lanjutan hingga 24 bulan. Dari jawaban yang diberikan ibu, diketahui 79,6\% ibu mengeluarkan ASI $\leq 3$ hari setelah melahirkan, dan memiliki alasan beragam dalam memberhentikan ASI sebelum 2 tahun (Yocom et al., 2018). Hasil penelitian di Desa Kalinaun Kecamatan Likupang Timur Kabupaten Minahasa Utara. juga menunjukkan bahwa $69,8 \%$ tidak ASI eksklusif (Tampi et al., 2017).

Upaya meningkatkan pemberian ASI dibutuhkan bantuan dan informasi yang mendukung, sehingga perempuan merasa yakin dapat menyusui bayinya dengan sukses. Keputusan Menteri Kesehatan, No. 450/Menkes/SK/VI/2004 tentang Pemberian ASI secara Eksklusif di Indonesia, menetapkan bahwa tenaga kesehatan agar menginformasikan kepada semua ibu yang baru melahirkan untuk memberikan ASI eksklusif dengan mengacu pada 10 langkah keberhasilan menyusui.

Kader posyandu adalah pengelola Posyandu dipilih dari dan oleh masyarakat pada saat musyawarah pembentukan Posyandu. Salah satu tugas melakukan penyuluhan kepada warga masyarakat agar pengetahuan dan tingkat kesehatan di masyarakat akan meningkat. Salah satu pesan kader yang harus disampaikan kepada ibu nifas atau ibu menyusui adalah tentang pemberian ASI Eksklusif dan tetap memberikan ASI sampai dengan 2 tahun pada saat bayi telah diperkenalkan makanan pendamping ASI.

Pelatihan pemberian ASI ekslusif selain meningkatkan pengetahuan, juga merupakan pemberian dukungan kepada ibu untuk menyusui.

Peserta pelatihan telah melakukan perannya sebagai motivator secara sukarela, dan ingin meningkatkan pengetahuan dan keterampilannya seperti diuraikan bahwa kegiatan ini diharapkan diadakan secara rutin dalam kegiatan Posyandu dan memberikan pendampingan bagi ibu menyusui.

\section{KESIMPULAN DAN SARAN}

Kesimpulan pada program ini adalah Penyuluhan dan pelatihan Kader Posyandu dapat meningkatkan pengetahuan menyusui sehingga mendorong para ibu untuk melakukan pemberian ASI Eksklusif. Saran yaitu untuk meningkatkan pengetahuan tentang pemberian ASI dapat terus dilakukan dengan melibatkan Tim Penggerak PKK Kelurahan berkolaborasi dengan bidan / petugas kesehatan dari Puskesmas untuk memberikan promosi atau penyuluhan tentang pemberian ASI. Kegiatan penyuluhan dapat dilaksanakan pada kegiatan Posyandu dengan mengikuti alur posyandu.

\section{UCAPAN TERIMAKASIH}

Terimakasih diucapkan kepada para pendukung kegiatan ini yaitu, Lembaga Penelitian dan Pengabdian pada Masyarakat (LPPM) Universitas Sam Ratulangi sebagai lembaga yang memfasilitasi terselenggaranya kegiatan ini. Program Kemitraan pada Masyarakat ini juga didukung oleh Lurah Tataaran II dan Kepala Puskesmas Koya, sebagai mitra yang bekerjasama dan mendukung penuh dalam program pengabdian masyarakat. 


\section{DAFTAR PUSTAKA}

Fikawati, S, Ahmad, S, Khaula, K.(2015). Gizi Ibu dan Bayi. Jakarta: PT RAJAGRAFINDO PERSADA

Kementerian Kesehatan R.I. 2013. Riset Kesehatan Dasar (RISKESDAS) 2013. Jakarta: Badan Penelitian dan Pengembangan Kesehatan.

Malonda, NSH., Rumayar, A.A.,Warouw, F. 2018. Faktor Risiko Kejadian Stunting Pada Anak Umur 6-24 Bulan Di Wilayah Kerja Puskesmas Koya Kecamatan Tondano Selatan Kabupaten Minahasa Provinsi Sulawesi Utara. LPPM Unsrat.

Mufdillah. 2017. Buku Pedoman Pemberdayaan Ibu Menyusui Pada Program ASI Eksklusif. Jogyakarta

Sudargo T, Aristasari T, Afifah A.2018. 1000 Hari Pertama Kehidupan. Jogyakarta: Gadjah Mada University Press.

Sugihantono, A. 2017. Kebijakan Kemenkes R.I: dalam upaya Pemberian makanan bayi dan anak untuk meningkatkan status gizi anak pada masa 1000 HPK. Dalam: Naskah Lengkap Kongres Nasional VII PDGMI. Manado

Tampi, C., Malonda,NSH., Ratag, BT. 2017. Hubungan Pemberian Asi Eksklusif Dengan Status Gizi Baduta Di Desa Kalinaun Kecamatan Likupang Timur Kabupaten Minahasa Utara https://ejournalhealth.com/index.php/me dkes/article/view/310. Vol 9, No 3 $\underline{(2017)}$

Yocom, J., Punuh, MI., Malonda, NSH. 2018. Hubungan Antara Riwayat Pemberian ASI Dengan Status Gizi Pada Anak Usia 24-59 Bulan Di Kecamatan Ratahan Kabupaten Minahasa Tenggara. https://ejournal.unsrat.ac.id/index.php/k esmas/article/view/22955. Vol 7, No 3 